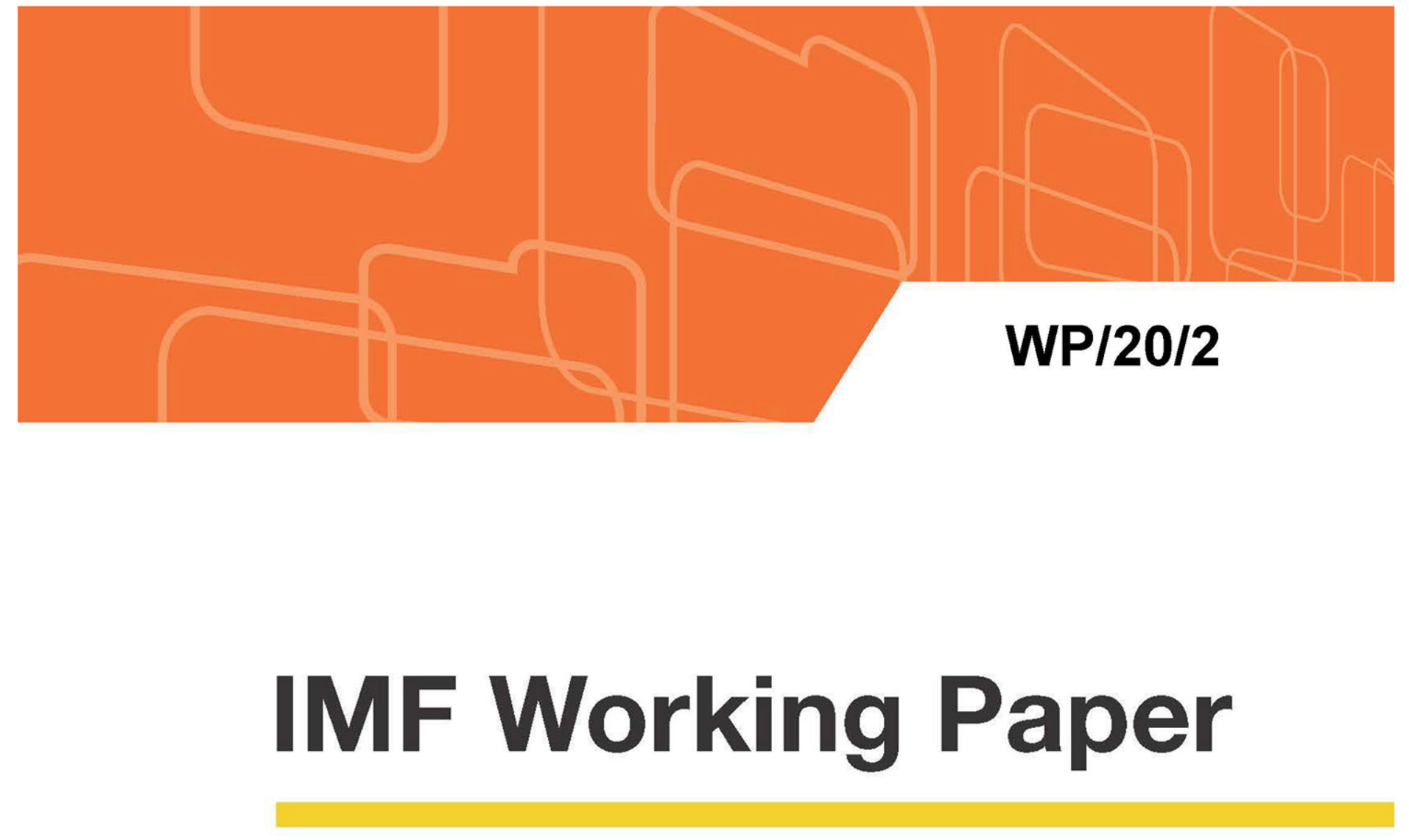

\title{
Crime and Output: Theory and Application to the Northern Triangle of Central America
}

by Dmitry Plotnikov

IMF Working Papers describe research in progress by the author(s) and are published to elicit comments and to encourage debate. The views expressed in IMF Working Papers are those of the author(s) and do not necessarily represent the views of the IMF, its Executive Board, or IMF management. 


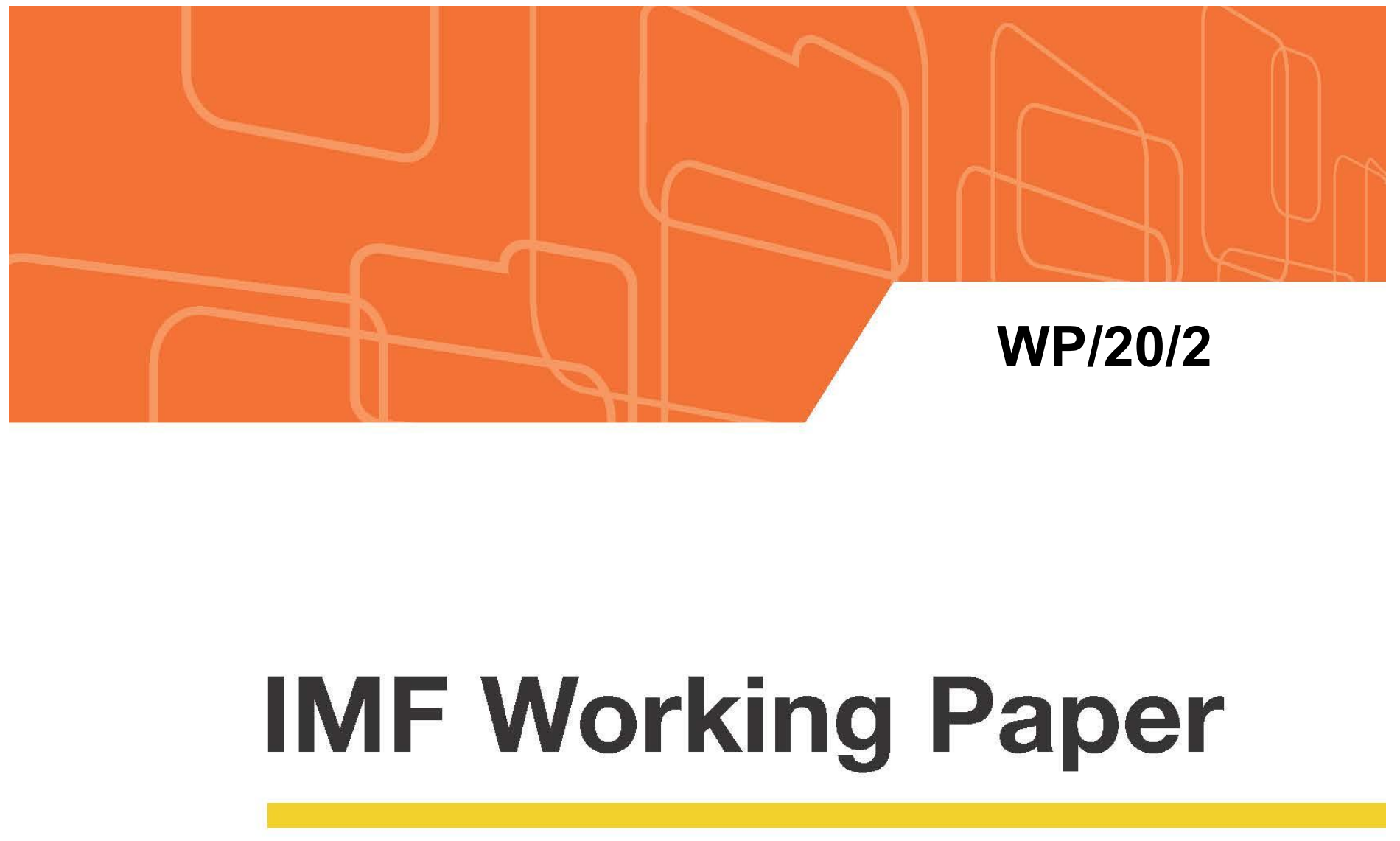

\section{Crime and Output: Theory and Application to the Northern Triangle of Central America}

by Dmitry Plotnikov

IMF Working Papers describe research in progress by the author(s) and are published to elicit comments and to encourage debate. The views expressed in IMF Working Papers are those of the author(s) and do not necessarily represent the views of the IMF, its Executive Board, or IMF management. 


\title{
IMF Working Paper
}

Western Hemisphere Department

\section{Crime and Output: Theory and Application to the Northern Triangle of Central America}

\section{Prepared by Dmitry Plotnikov}

Authorized for distribution by Ravi Balakrishnan

January 2020

\section{IMF Working Papers describe research in progress by the author(s) and are published to} elicit comments and to encourage debate. The views expressed in IMF Working Papers are those of the author(s) and do not necessarily represent the views of the IMF, its Executive Board, or IMF management.

\begin{abstract}
This paper presents a structural model of crime and output. Individuals make an occupational choice between criminal and legal activities. The return to becoming a criminal is endogenously determined in a general equilibrium together with the level of crime and economic activity. I calibrate the model to the Northern Triangle countries and conduct several policy experiments. I find that for a country like Honduras crime reduces GDP by about 3 percent through its negative effect on employment indirectly, in addition to direct costs of crime associated with material losses, which are in line with literature estimates. Also, the model generates a non-linear effect of crime on output and vice versa. On average I find that a one percent increase in output per capita implies about $1 / 2$ percent decline in crime, while a decrease of about 5 percent in crime leads to about one percent increase in output per capita. These positive effects are larger if the initial level of crime is larger.

JEL Classification Numbers: J24, J30, E26

Keywords: Crime, Employment, Growth

Author's E-Mail Address: dplotnikov@imf.org
\end{abstract}




\section{INTRODUCTION}

Persistent crime in Central America and, especially in the Northern triangle - Honduras, El Salvador, and Guatemala - presents one of the biggest challenges to economic development. Its importance in the Northern Triangle is hard to underestimate: these countries account for $41 / 2$ percent of the world homicides but only $1 / 2$ percent of the world's population. According to the 2016 Latinobarometro survey, crime and corruption surpass employment and other economic issues as more important development issues in the Northern Triangle and the Dominican Republic (see figure). In addition, crime tends to disproportionately impact poorer individuals due to their inability to protect themselves, thus exacerbating inequality (Lagarde (2015)). Given that at least $1 / 3$ of population in the Central America lives in poverty, reducing crime is of utmost importance.

Although homicide rates in the Northern Triangle in 2018 were still ones of the highest in the world they have declined in most countries since 2011 (see figure). ${ }^{1}$ Honduras and El Salvador homicide rates (40 and 51 per 100,000 inhabitants in 2018, respectively) are significantly above the LAC average ( 24 per 100,000 in 2016). ${ }^{2}$

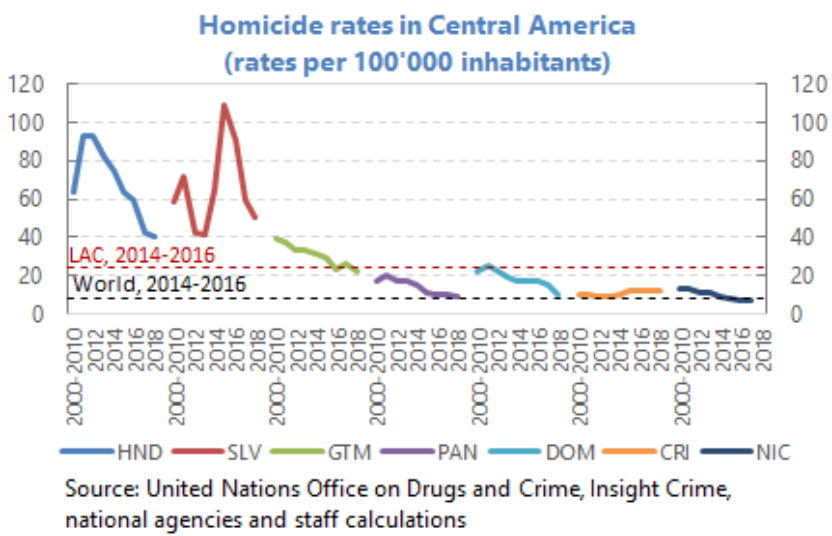

Crime and economics are intrinsically linked - a fact known since Becker (1968) and especially important for the Northern Triangle given the high crime levels. In particular, individuals' choice between productive and criminal activity depends on availability of both productive and criminal opportunities, effectiveness of the judicial system and quality of the prison system and current crime and labor market policies among other factors. In other words, this choice is endogenous. Thus any policy intervention and its projected payoffs and costs should include individuals' response to changed incentives. Specifically, policies not intended to affect the crime level, such as labor market policies, can do so indirectly. The reverse is also true: crime-related policies can affect economic activity.

The three main contributions of this paper are to (1) evaluate indirect costs of crime (and compare implied estimates of direct costs of crime with the ones in the literature), (2) estimate the causal and potentially nonlinear relationship between crime and output, and (3) assess effects of several crime and labor market policies on crime and output in the Northern Triangle countries. I do this by constructing a general equilibrium model - based on the labor search framework (e.g., Pissarides (2000)) - in which the occupational choice between crime and economic activity is endogenous. The choice depends on the payoffs

\footnotetext{
${ }^{1}$ Only El Salvador in 2013-2015 and Costa Rica in 2013-2017 experienced an increase in the homicide rate. Additionally, Nicaragua has not released the 2018 data, which is likely to show an uptick due to the ongoing political crisis. (C) International Monetary Fund. Not for Redistribution ${ }^{2}$ See IMF (2019) for discussion of factors behind dvnamics of homicide rates in Honduras and El Salvador
} 
associated with each activity that in turn depend on fundamentals as well as the set of current policies. If one of the two payoffs becomes larger, the flow to this activity increases, until a new equilibrium is reached. I calibrate the model to the Northern Triangle countries to study its numerical implications.

\section{RELATED FACTS AND Literature}

What explains high crime levels in the Northern Triangle? A major factor is drug trafficking. The 2016 U.S. State Department International Narcotics Control Strategy Report estimates that 90 percent of the cocaine trafficked to the United States in the first half of 2015 passed through Central America. For example, UNODC (2012) estimates the total value of cocaine that passed through Honduras and Guatemala in 2010 to be 13 and 10 percent of Honduran and Guatemalan GDP respectively or nearly $2 / 3$ of the total spending on crime prevention of the entire region in the same year. ${ }^{3}$

How large are estimated costs of crime in the Northern Triangle? Acevedo (2008) estimates losses of about ten percent of GDP per year in the Northern Triangle due to health costs, public and private security and justice costs, as well as material losses. Some recent studies estimating total costs as high as 40 percent of GDP (IEP (2018)).

Because the choice between productive and criminal activities is endogenous, the existing estimates of crime costs that ignore this endogeneity might be underestimated. Theoretically, there are direct and indirect costs of crime. The direct costs include output (goods) and resources (time and wages of both victims and criminals) lost due to theft, robbery, murder; resources spent on security costs - public and private - that otherwise could have been used on productive activity. The direct costs are easier to calculate and several estimates are available in the literature (e.g., Acevedo (2008), World Bank (2011), Penate and others (2016), IDB (2017), IDB (2017), IEP (2014, 2016, 2018)).

The (potentially larger) indirect costs include lower equilibrium levels of economic activity as individuals internalize direct costs of crime. Examples include lower employment opportunities, higher outward migration, erosion of institutions and corruption. All these outcomes, in turn, exacerbate crime, generating a vicious cycle. These indirect costs are harder to measure since they require additional assumptions to estimate the corresponding counterfactual environment against which the cost is assessed (see, for example Penate and others (2016)). Having a general equilibrium model, like the one in this paper, solves this problem.

The link between output and crime is also likely to be nonlinear: as security situation improves crime may be initially easier and then harder to eradicate. Moreover, lower and non-violent crime levels might matter increasingly less if legal economic opportunities abound.

A search framework employed in this paper presents a natural environment to model transitions between employment, unemployment and criminal activity for individuals and vacancy creation decision for firms. Representative firms and individuals populate the economy in the model. Individuals are amoral and choose occupation (productive or criminal)

\footnotetext{
${ }^{3} \mathrm{El}$ Salvador is different in this respect - the total value of cocaine that is estimated to pass through the country in that year was less than one percent of GDP.
} 
based on the associated payoffs. In the formal labor market firms open vacancies and individuals looking for employment are randomly matched together via a stochastic technology. When matched, a worker and a firm bargain over the surplus and start production. Output, including firms' profit and wages, is appropriated by criminals with a probability that positively depends on the aggregate number of criminals. For simplicity, total output stolen by criminals is uniformly distributed across them. With some probability, reflecting quality of the judicial system, criminals go to jail where they earn zero income. Prisoners leave jail with a probability that reflects leniency of the criminal justice system and become unemployed.

To my knowledge only a few attempts exist in the literature to model interaction between crime and productive activity. Engelhardt, Rocheteau, and Rupert (2008) and Huang, Laing, and Wang (2004) present search frameworks calibrated to data from the U.S. that are the closest to the current paper. Both papers focus entirely on how employment, not output or growth, interacts with crime.

\section{MODEL}

The model builds on the standard Diamond-Mortensen-Pissaridies (DMP) framework (see, for example, Pissarides (2000)). There are two types of agents: individuals and firms. Both agents are risk-neutral. In every period, a firm either produces or searches for a worker. An individual is either employed, unemployed, engages in criminal activity or in jail. For simplicity, I describe the economy in the steady state and later conduct policy experiments via comparative statics.

\section{A. Firms}

The labor market operates as in the standard labor search model. Representative firms freely enter the labor market, but need to post a vacancy, which costs $c$ per period, and search for a worker to start production. Each firm requires only one worker. Similarly, individuals who are currently unemployed and are looking to become employed need to search for a job. Unemployed individuals and firms with vacancies meet at random. The number of matches per period is determined by a concave, homogeneous of degree one matching function $m=m(u, v)$, where $u$ is the number of unemployed individuals and $v$ is the number of firms with vacancies. Therefore, the probability of filling an existing vacancy per period is $q=m / v=m(u / v, 1)=m(1 / \theta, 1)=q(\theta)$, where $\theta=v / u$ is the labor market tightness. Similarly, the probability of being matched with a firm for any unemployed individual looking for a job equals to $m / u=\theta q(\theta)$.

Then, the present-discounted value of expected profit from an occupied job, $V_{J}$, is

$$
V_{J}=\frac{c}{q(\theta)}=\frac{(1-\alpha)(p-w)}{r+\lambda}
$$


where $c$ is the cost of open vacancy per period, $p$ is labor productivity, $w$ is the wage of a worker, $r$ is the discount rate, $\lambda$ is the job destruction rate and $0<\alpha<1$ is the crime rate. Equation (1) determines how many jobs are created in the economy.

The LHS of Equation (1) represents the cost of an open vacancy, since $q(\theta)$ is the probability of filling it every period. The RHS of the equation represents the value of a filled job. The filled job yields net return $(1-\alpha)(p-w)$ per period, where $w$ is the labor cost of the firm. All existing jobs run an exogenous risk $\lambda$ of being destroyed every period. The free-entry condition implies that the present-discounted value of a firm that has not found a worker is zero and therefore the LHS should be equal to the RHS. Additionally, I assume that after output is produced criminals steal it with probability $\alpha$. If this happens, both the firm and the worker receive zero income in this period. With probability $1-\alpha$, output $p$ is produced with no disruptions and is split between wage $w$ and firm's profit $p-w$. Thus, the criminal activity in the model can be interpreted as any economic crime that disrupts production, such as extortion by gangs via a so called "war tax", financial fraud and theft of financial or non-financial assets, or a physical robbery or burglary of an establishment. The only difference between equation (1) and its analog in the standard DMP model is that in the DMP framework $\alpha=0$ implying no output disruptions due to crime. $^{4}$

Equation (1) already demonstrates a detrimental indirect effect of crime on job creation that is not captured in direct crime cost calculations (see, for example, IDB (2017)). The expected profit from a match is lower in the presence of crime. As a result fewer firms will post vacancies, which in equilibrium leads to lower employment and output levels than in the standard model.

An important distinction between the model in this paper and the DMP model is that in the present model the vacancy cost $c$ is constant and does not proportionally increase with labor productivity, $p$. In the standard model proportionality implies that labor productivity changes are irrelevant for all endogenous variables. However, this assumption seems to be too strong in the context of the Central American labor market. First, given the level of development, low human capital level and high informality, significant hiring is done through visual signs outside establishments, personal referrals, or over the Internet. The cost of such vacancies should be close to constant in the medium-term. Second, hiring expenses in developed countries that are likely to increase with output and wages - such as employee relocation costs, travel expenses for applicants, sign-on bonuses, third party recruiter fees to be negligible for most of the Central America.

\section{B. Individuals}

In this subsection I describe how individuals transition between unemployment and employment. Then, I discuss transition into and from criminal activity. Without loss of generality, the population size is normalized to one.

\footnotetext{
${ }^{4}$ As it will be shown later, in the presence of crime the observed output equals $\alpha p$. Thus, $\alpha$ ca be interepreted as the cost of violence expressed in percent of GDP. This can potentially include security (public and private), health costs etc.
} 


\section{Productive Activity}

Unemployed individuals that decide to look for a job receive $z$ per period that represents leisure and unemployment benefits. With probability $\theta q(\theta)$ an unemployed individual finds a job and with probability $1-\theta q(\theta)$ the individual remains unemployed in the next period. The unemployed do not incur searching costs, in contrast to firms.

Employed individuals receive wage $w$ per period with probability $1-\alpha$, if the firm at which they work is not affected by crime and zero with probability $\alpha$, if the firm is victimized. ${ }^{5}$ After the crime uncertainty is realized the match is destroyed with exogenous probability $\lambda$. If the match is destroyed the worker becomes unemployed and the firm starts searching for another worker. These assumptions imply

$$
\begin{gathered}
V_{u}=z+\frac{1}{1+r}\left(\theta q(\theta) V_{w}+(1-\theta q(\theta)) V_{u}\right) \\
V_{w}=(1-\alpha) w+\frac{1}{1+r}\left((1-\lambda) V_{w}+\lambda V_{u}\right)
\end{gathered}
$$

Solving for the present values of being employed $V_{w}$, and unemployed $V_{u}$, as functions of the discount rate $r$, the job destruction rate $\lambda$, labor market tightness $\theta$, wage $w$, crime rate $\alpha$ and leisure value flow $z$ gives

$$
\begin{aligned}
& r V_{w}=(1+r) \frac{z \lambda+(1-\alpha) w(r+\theta q(\theta))}{\lambda+r+\theta q(\theta)} \\
& r V_{u}=(1+r) \frac{z(\lambda+r)+(1-\alpha) w \theta q(\theta)}{\lambda+r+\theta q(\theta)}
\end{aligned}
$$

It can be shown that both present values of employed and unemployed are lower than in the standard model, since the labor market tightness $\theta$ and the expected wage are lower in the presence of crime $(1-\alpha<1)$. Wage is determined using Nash bargaining as in the standard DMP model. Denote $\beta$ the bargaining weight of individuals. Then wage is determined by the following equation:

$$
V_{w}-V_{u}=\beta\left(V_{J}+V_{w}-V_{u}\right)
$$

where the expression in parenthesis on the RHS is the total aggregate surplus created from the match between a firm and a worker. ${ }^{6}$ This equation yields the following aggregate equilibrium wage equation:

$$
(1-\alpha) w=(1-\beta) z+\beta((1-\alpha) p+c \theta)
$$

\footnotetext{
${ }^{5}$ Except the associated loss of resources, there is no other - e.g., psychological - cost for victims.

${ }^{6}$ Recall that the present value of an open vacancy is zero because of the free entry condition.
} 
Intuitively, Equation (4) is an equivalent of the labor supply equation in the model. ${ }^{7}$ It says that the expected wage is a weighted average of worker's income if unemployed, $z$, and the sum of the expected match surplus $(1-\alpha) p$ and the average hiring $\operatorname{cost} c \theta$ per unemployed worker. ${ }^{8}$ Clearly, if the worker's bargaining weight decreases (and, therefore, the firm's bargaining power increases) the wage decreases. In the extreme case when $\beta=$ 0 , individuals are indifferent between working and staying unemployed as both activities result in the same income. As in the standard model, a worker is rewarded for the saving of hiring cost that the firm receives when the match is formed, $c \theta$.

The wage, represented by Equation (4), is the result of ex-ante bargaining (before the crime uncertainty is realized) and, therefore, is set in expected terms. ${ }^{9}$ The LHS represents the expected wage in the presence of crime and the RHS includes the expected surplus $(1-\alpha) p$. As with the previous equations, setting $\alpha=0$ results in the standard model wage equation.

Crime reduces the number of vacancies for a given wage and increases wage pressures, resulting in a lower labor market tightness. To see how crime affects the labor market graphically Figure 1 plots the job creation equation (1) and the wage curve (4) in the wage-labor market tightness space for a given level of crime. The dashed lines correspond to the model with no crime $(\alpha=0)$ and the solid lines to the model with crime. For a given level of crime equation (1) implies an inverse relationship between wages and labor tightness. ${ }^{10}$ The presence of crime lowers the number of vacancies for a given wage. Graphically, crime shifts the job creation curve to the left. The wage curve is linear in $\theta$ for

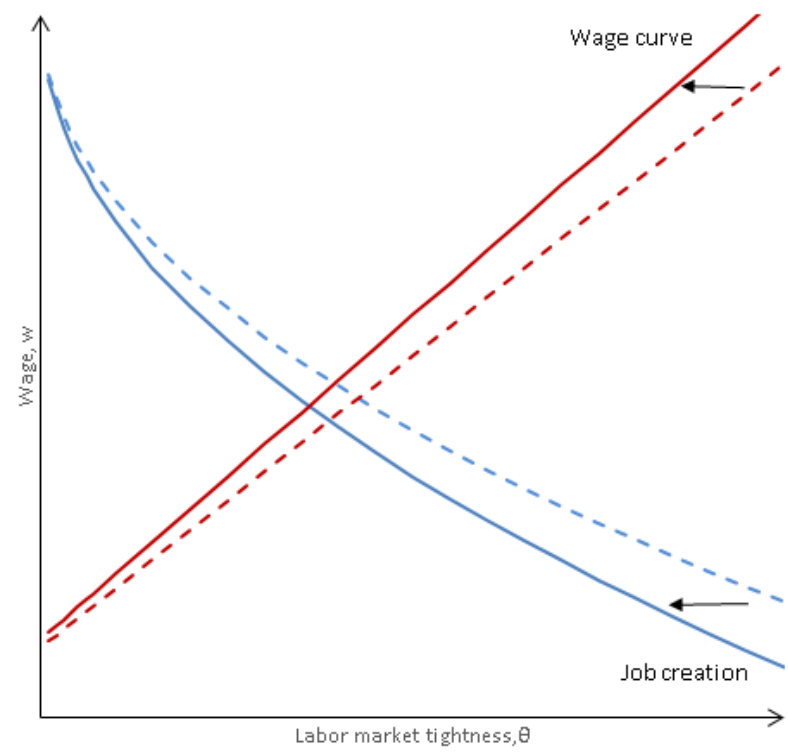

Figure 1. The labor market in the presence of crime (solid lines). The dashed lines correspond to the model with no crime a given level of crime. Higher crime makes individual demand higher wages shifting the wage schedule left and up. In equilibrium crime results in a lower labor tightness, so that $\theta=\theta(\alpha)$ is a decreasing function of $\alpha$.

How crime affects wages is less clear and the direction of the effect depends on the model parameters. For example, all else equal higher leisure value $z$ increases wages more in the presence of crime relative to the standard model (see Equation (4)).

Note that $V_{w}>V_{u}$ if and only if $(1-\alpha) w>z$ from Equations (2), (3). A sufficient condition for the latter is that $(1-\alpha) p>z$ which is satisfied for any reasonable calibration since $\alpha$ should be close to zero. Graphically (Figure 1) this condition means that the intercept of the wage curve $\left((1-\beta) \frac{z}{1-\alpha}\right)$ is always below the point where the job creation curve crosses the $\mathrm{y}$-axis $(p)$.

\footnotetext{
${ }^{7}$ Equation (1) is an equivalent of labor demand.

${ }^{8}$ Since $c \theta=\frac{c v}{u}$ and $c v$ is the total vacancy cost in the economy.

${ }^{9}$ Remember that this is the only option since the employer does not insure the worker against the crime risk.

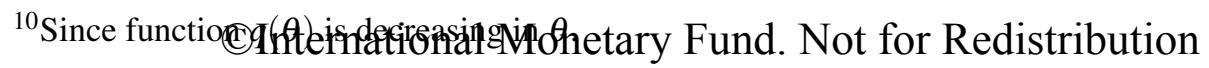




\section{Criminal Activity}

Individuals that decide to engage in criminal activity must become full-time criminals (i.e. crime is not a part-time activity in the model). This assumption reflects the prevalence of gangs in Central America. The probability of becoming a criminal, $b$, is endogenous and is such that individuals are indifferent between searching for a job and becoming a criminal. ${ }^{11}$ Active criminals earn endogenous income $w_{B}$ per period and go to jail with exogenous probability $\eta$. If the present value of being a criminal is $V_{B}$ and the present value of being in jail is $V_{C}$, then

$$
V_{B}=w_{B}+\frac{1}{1+r}\left(\eta V_{C}+(1-\eta) V_{B}\right)
$$

The parameter $0<\eta<1$ measures overall effectiveness of the judicial system to catch and prosecute criminals. Higher values of $\eta$ correspond to more effective police and judicial system. Later I show that once an individual becomes a criminal, he would not want to become unemployed to look for a job because this will yield a lower return. If not prosecuted in a given period, an active criminal continues to be a criminal next period.

Prosecuted criminals are sent to jail where they earn zero income and transition into unemployment pool with probability $\xi$. Parameter $0<\xi<1$ measures harshness of punishment and average duration of time in jail once a criminal is convicted. Lower values of $\xi$ correspond to longer average sentences.

$$
V_{C}=\frac{1}{1+r}\left(\xi V_{u}+(1-\xi) V_{C}\right)
$$

Solving for $V_{B}$ and $V_{C}$ gives:

$$
V_{B}=\frac{(1+r) w_{B}+\eta V_{C}}{\eta+r}=\frac{(1+r) w_{B}+\eta \frac{\xi}{r+\xi} V_{u}}{\eta+r}
$$

How are criminals' income, $w_{B}$, and the crime rate $\alpha$ determined in equilibrium? For simplicity I assume that the entire stolen output, which includes both wages and firms' profits, is uniformly distributed across active criminals:

$$
w_{B}=\frac{p \alpha N_{L}}{N_{B}}
$$

where $N_{L}$ is the number of producing firms - which equals to the number of employed individuals, - and $N_{B}$ is the number of active criminals. The numerator of the fraction corresponds to the total output stolen from firms. It is equal to the output of a representative firm, $p$, multiplied by the number of affected firms, $\alpha N_{L}$. Also for simplicity it is

\footnotetext{
${ }^{11}$ This condition is required for co-existence of productive and criminal activities in a steady state, because all individuals are identical.
} 
assumed that no resources are lost during transition between the productive and criminal sectors. ${ }^{12}$ To close the model, one needs to specify how the crime rate depends on the total number of active criminals, $\alpha=\alpha\left(N_{B}\right) .{ }^{13}$ Clearly, $\alpha\left(N_{B}\right)$ should be an increasing function since more criminals should imply a higher victimization probability. Absence of criminals should imply absence of crime, thus $\alpha(0)=0$. Similarly, if the entire population are criminals, no output is produced and, therefore, $\alpha(1)=1$. To ensure existence of crime in equilibrium, it is sufficient to assume that

$$
\lim _{N_{B} \rightarrow 0} \frac{\alpha\left(N_{B}\right)}{N_{B}}=\infty
$$

If these assumptions hold, equation (7) means that if there are no criminals, the first criminal will make an infinite profit ensuring existence of crime in any equilibrium. Similarly, it is necessary that $\alpha\left(N_{B}\right) / N_{B}$ is a decreasing function of $N_{B}$ for existence of productive activity. The latter property means that even though two criminals together "steal" more output than one, they receive less income per person.

\section{E. Occupational choice}

The individuals in the model are amoral and only consider monetary payoffs when choosing an occupation. Thus, given that all individuals are identical, for productive and criminal activities to co-exist in the steady state the unemployed must be indifferent between searching for a job or becoming a criminal. Therefore, the following condition holds:

$$
b V_{B}+(1-b) V_{u}=\theta q(\theta) V_{w}+(1-\theta q(\theta)) V_{u}
$$

The LHS of this equation is the expected present value of becoming a criminal. The RHS is the expected present value of becoming a law-abiding productive member of the economy. The condition above ensures that all unemployed individuals search for both opportunities at the same time.

Equation (9) determines the effective transition rate to criminal activity, $b$. That means that every period a share $b$ of unemployed individuals receive an opportunity to become criminals, which they always accept since $V_{B}>V_{u}$. For the moment that I am agnostic about the exact mechanism that determines $b$. I discuss it further in subsection III.G.

Note that employed individuals never would like to quit their job to become criminals. Indeed, if an employed individual quits his expected payoff is $b V_{B}+(1-b) V_{u}<V_{w}$ since $V_{u}<V_{w}$ and Equation (9).

\footnotetext{
${ }^{12}$ Such a "transaction" cost can also correspond to security costs spent by firm or government since these resources are neither part of productive individuals' income nor part of criminals' income.

${ }^{13}$ Since every individual is infinitesimal, they cannot influence $N_{B}$.
} 


\section{F. Aggregate state transitions}

In this section, I describe steady state relationships between flow and stocks among the possible four states for individuals.

The main idea is that for an equilibrium to be stationary, the sum of all inflows in every state should be equal to the sum of all outflows from this state. If this condition is violated for any state, the number of individuals in this state will either decrease or increase over time, contradicting stationarity.

Since the population size is fixed at one, the sum of individuals in all states equals one as well:

$$
N_{L}+u+N_{B}+N_{C}=1
$$

where I defined the number of individuals in jail as $N_{C}$ in addition to the earlier notations of the number of employed individuals as $N_{L}$, the number of criminals as $N_{B}$ and the number of unemployed individuals as $u$.

Stability of unemployment implies that the inflows in the unemployment pool equal to the corresponfing outflows. The inflows include workers whose match was destroyed and individuals released from jail. The outflows are either because individuals found a job or became criminals. Therefore, in the steady state:

$$
\lambda N_{L}+\xi N_{c}=(\theta q(\theta)+b) u
$$

Switching to the number of criminals in the economy, the number of criminals increases because individuals from unemployment pool decide to engage in criminal activity and decreases because criminals are convicted and sent to jail. In the steady state

$$
b u=\eta N_{B}
$$

The number of individuals in jail increases due to inflow of convicted criminals and decreases as convicts are released. In the steady state these flows must be equal implying

$$
\eta N_{B}=\xi N_{c}
$$

Figure 2 summarizes flows within the model with corresponding per period rates.

It follows from Equations (10) - (13) and the monotonicity of $\theta$ as a function of crime that, in the economy with crime, employment (and, therefore, output) is always lower than in the absence of crime. Indeed, combining the equations above, employment in the presence of crime equals to

$$
N_{L}=\frac{\theta q(\theta)}{\lambda+\theta q(\theta)}\left[1-(1+\eta / \xi) N_{b}\right]
$$


Firms
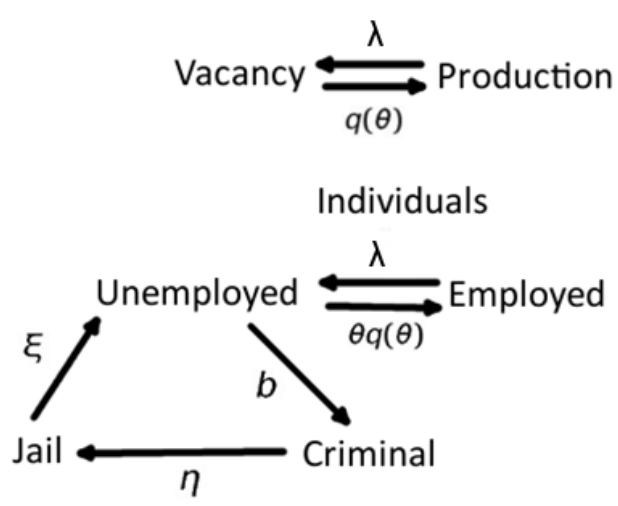

Figure 2. Flow chart of state transitions in the model

Since the labor tightness level is always lower in the presence of crime, as argued in the previous subsection, and the job finding rate $\theta q(\theta)$ is an increasing function of $\theta$, employment is a decreasing function of crime.

The equation above also implies that for existence of an equilibrium it is necessary that $N_{B}<\xi / \xi+\eta$. This restriction means that the crime rate must be sufficiently small to ensure existence of production.

\section{G. Equilibrium}

The equilibrium in the model is characterized by the combination of the legal labor market response to the crime rate and the criminal sector attractiveness given legal opportunities. The labor market response can be characterized by a decreasing function $\theta(\alpha)$, meaning that higher crime lowers labor market tightness, discussed in subsection III.C. Similarly, the criminal sector response is a decreasing function $\alpha(\theta)$, meaning that better economic opportunities lead to lower crime. The combination of the two functions results in a unique equilibrium $(\alpha, \theta)$. I discuss function $\alpha(\theta)$ in this subsection.

The equilibrium in the criminal sector can be represented by a combination of criminal supply and demand (see Figure 3). Equation (12) determines criminal supply. It balances the inflow in the criminal activity per person $b$ with the total outflow $\left(\eta N_{B}\right)$ and the number of potential criminals - the unemployment pool. Lower unemployment means higher possibility of receiving a criminal offer, $b$. Combining this equation with the expression for equilibrium employment (Equation (14)), it can be shown that the resulting function $b_{s}=b_{s}\left(N_{B}, \theta\right)$ increases in both arguments. ${ }^{14}$ This is because higher existing stock of criminals means larger absolute outflows from criminal activity. Better economic conditions (higher $\theta$ ) result in a smaller unemployment pool, increasing the conversion rate per person.

Criminal demand is determined by Equation (9), which describes attractiveness of criminal activities for unemployed relative to legal activity. Substituting expressions of $V_{B}$, $V_{w}, V_{u}, w$ and $w_{b}$ one can express the conversion rate $b$ as a function of $N_{B}$ and $\theta$. It can be shown that this function $b=b_{d}\left(N_{B}, \theta\right)$ decreases in $N_{B}$ given the assumptions for

\footnotetext{
${ }^{14}$ Moreover, $b_{s}(0, \theta)=0$ and $\lim _{N_{b} \rightarrow \frac{\xi}{\xi+\eta}} b_{s}\left(N_{B}, \theta\right)=+\infty$.
} 
$\alpha=\alpha\left(N_{B}\right){ }^{15}$ The demand for criminal activities decreases in $N_{B}$ because higher crime lowers both income of criminals per period $\left(w_{b}\right)$ and value of being unemployed $V_{u}$ relative to the return from working $\left(V_{w}-V_{u}\right)$. This ensures that the criminal supply and demand always cross resulting in an equilibrium crime rate.

As Figure 3 shows, an improvement in labor opportunities (an increase in $\theta$ ), does not lower demand for criminal activities for all levels of crime $N_{b}$. Two forces are at play here. On the one hand an improvement in economic opportunities naturally makes employment more attractive. On the other hand, return of criminal activities increases because firms and workers become richer. Thus for higher crime levels, individuals prefer to switch to legal activities as criminal income per person is relatively low. For low crime levels, more individuals turn to crime as it is more

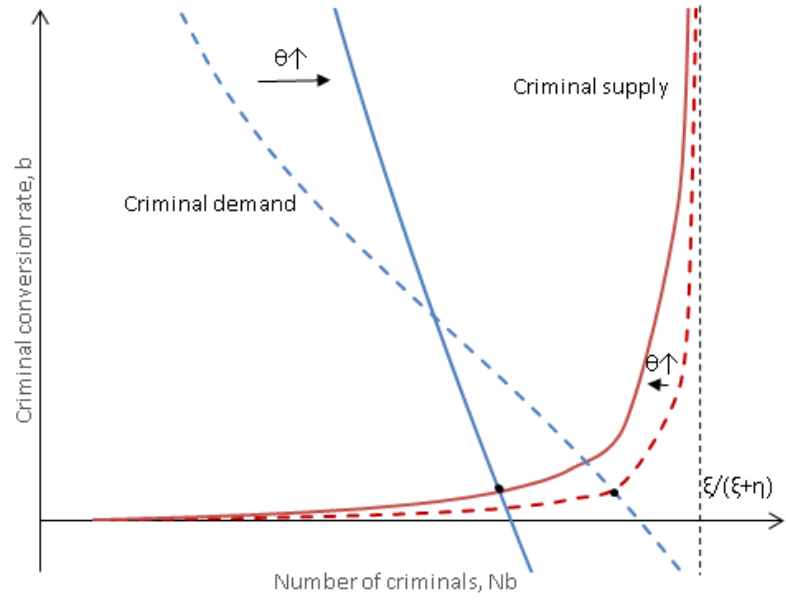

Figure 3. The criminal market given economic opportunities. The dashed lines correspond to worse economic conditions (lower $\theta$ ) profitable to steal than to find a job.

In practice adverse effects of better economic conditions on crime for low crime levels should be small. They can also be completely avoided if quality of the judicial system $(\eta)$ keeps up with the improvement in economic conditions.

It can be shown that the slope of the criminal demand curve increases in the level of crime resulting in the decreasing equilibrium criminal sector response function $\alpha(\theta)$. It follows from the fact that $\alpha$ is an increasing function in $N_{B}$ and the monotonic properties of the criminal demand and supply schedules discussed above.

\section{Calibration}

Given the simplicity of the model, relative similarities in the economic structure of the Northern Triangle countries, I calibrate the model to three countries at different time periods to highlight implications of different crime levels for the respective economies.

I start with calibrating the model to Honduras in 2016, which I would like to think of a "baseline" high-crime case. Both El Salvador and Honduras in the past have experienced homicide rates close to 60 as Honduras did in 2016, making this case relevant. Moreover, Penate and others (2016) explicitly calculate direct and indirect costs (under specific assumptions) for El Salvador in 2014 when it had a similar homicide rate - 64.2. The second calibration is for El Salvador in 2015, when the homicide rate peaked at 108.6. This corresponds to the extremely high crime case. Finally, the third calibration case is Guatemala over 2015-2017 when the homicide rate was oscillating near 30, slightly above the LAC average in 2014-16. representing lower crime case. In the rest of the paper I refer

\footnotetext{
${ }^{15}$ Also it can be shown that $\lim _{N_{B} \rightarrow 0} b_{d}\left(N_{B}, \theta\right)=+\infty$ and $b_{d}\left(\frac{\xi}{\xi+\eta}, \theta\right)<0$.
} 
to these calibrations as simply "Honduras", "El Salvador" and "Guatemala", however they capture these countries in very specific circumstances as discussed above.

The calibration for all three countries is done in two steps. First, the model without crime is calibrated. Second, values for crime-related parameters are calibrated.

Without loss of generality, I normalize the productivity and, therefore underlying GDP per capita to one. Thus, effects of all policies will be measured relative to the current level of GDP per capita.

Since neither country has unemployment benefits, I proxy the leisure flow of being unemployed by social benefits in case of Honduras (see Table 3 in IMF (2018)), current non-pension transfers in case of El Salvador (see Table 4 in IMF (2016)) and conditional cash transfers in case of Guatemala. ${ }^{16}$ For example, in Honduras in 2015 it was equivalent to 3.2 percent of GDP and is expected to remain on a similar level in the medium term. Therefore, $z=0.032 p$. Similarly $z=0.02 p$ for El Salvador and $z=0.002 p$ for Guatemala.

I set the discount rate to be equivalent to the annual rate: 2.2 percent for Honduras which is equal to the real interbank interest rate in 2015-16; 6.0 percent for El Salvador, which is equal to the average real interest rate between deposit and loan rates in 2015; 5.3 percent rate for Guatemala, which is equal to the average real interest rate between deposit and lending rates in 2015-2017.

Since I do not have information on average job duration in the Northern Triangle I set it to be similar to the one in the U.S.: 2.5 years (see Shimer (2005)). This assumption pins down the job destruction rate, $\lambda$.

I assume a standard Cobb-Douglas matching function, $q(\theta)=A \theta^{-s}$. As explained in Shimer (2005), the labor market tightness in the steady state can be normalized to one. Then the job destruction rate and the unemployment rate (7.3 percent for Honduras, 7 percent for El Salvador and 3 percent for Guatemala) determine the scale parameter $A$ for each country. The elasticity parameter $s$ is set to $1 / 2$ for all countries. Similarly, the workers bargaining weight $\beta=1 / 2$ implying equal split of the surplus between the firm and the worker and welfare maximization in a model with no crime (Hosios (1990)). Vacancy cost $c$ is pinned down using Equation (1) assuming no crime.

By calibrating the non-crime parameters in the model as described above, I can compare the model's outcome relative to the model with no crime. To calibrate the crime-related parameters $\xi$ and $\eta$, I explicitly focus on homicides. By focusing on homicides I minimize measurement error and misreporting. Homicide rate should also be correlated with other types of crime. I can also compare implied estimates of homicide costs with existing literature (e.g. Acevedo (2008), IDB (2017), Penate and others (2016)). Moreover, rough estimates of how many homicides are currently prosecuted exist. Nazario (2016) estimates it at 4 percent for Honduras, El Faro (2016) estimates it at 6.1 percent for El Sal-

\footnotetext{
${ }^{16} \mathrm{http} / / /$ www.minfin.gob.gt/images/archivos/estadisticas/doc209.pdf
} 


\begin{tabular}{|c|c|c|c|c|}
\hline \multirow{2}{*}{ Parameter name } & \multirow{2}{*}{ Symbol } & \multicolumn{3}{|c|}{ Target } \\
\hline & & Honduras, 2016 & El Salvador, 2015 & Guatemala, 2015-17 \\
\hline Discount factor & $r$ & 2.2 percent $^{1}$ & 6.0 percent $^{1}$ & 5.7 percent $^{1}$ \\
\hline Job destruction rate & $\lambda$ & \multicolumn{3}{|c|}{ Job average duration of 2.5 years } \\
\hline Outside option, leisure & $z$ & .2 percent of GDP & 2.0 percent of GDP & 0.2 percent of GDP \\
\hline Worker's bargainin & $\beta$ & \multicolumn{3}{|c|}{ Surplus is split equally between worker and firm } \\
\hline Effectiveness of the judicial system & $\eta$ & 4 percent $^{2}$ & 6.1 percent $^{2}$ & 5.7 percent $^{2}$ \\
\hline Release rate from jail & $\dot{\xi}$ & \multicolumn{3}{|c|}{ Average imprisonment duration is 15 years } \\
\hline Vacancy cost per period & $c$ & \multicolumn{3}{|c|}{ Implied by other parameters and Equation (1) } \\
\hline Unemployment rate & $u$ & 7.3 percent & 7.0 percent & 3.0 percent \\
\hline Matching function & $\begin{array}{l}q(\theta)= \\
=A \theta^{-s}\end{array}$ & \multicolumn{3}{|c|}{$\begin{array}{l}\text { The scaling factor } \mathrm{A} \text { is implied by } \lambda \text { and the unemployment rate } \\
\text { The matching function is assumed to be equally elastic }(s=0.5)\end{array}$} \\
\hline Effectiveness of criminals & $\alpha\left(N_{B}\right)=N_{B}^{\mu}$ & \multicolumn{3}{|c|}{ Parameter $\mu$ is assumed to be $1 / 2$} \\
\hline
\end{tabular}

Table 1. Summary of calibrated parameters. ${ }^{1}$ Annual real interest rates. ${ }^{2}$ Share of murders that are prosecuted per year

vador and I estimate it to be 5.7 percent for Guatemala based on the National Statistical Agency (INE) data ${ }^{17}$.

I set $\xi$ to imply 15 years as the average prison sentence for all three countries, the minimum established in the respective penal codes. The Honduras and El Salvador penal codes set the sentence for a murder between 15 and 20 years, while the Guatemala sets the murder sentence between 15 and 40 years ${ }^{18}$. But since criminals are likely to receive more lenient sentences on top of involvement of minors as hitmen for whom the maximum sentence is capped at 6 years in case of Guatemala (InSight Crime (2017)), I set $\xi$ to imply the minimum sentence in all countries as the average prison sentence.

I assume that the amount of crime depends on the total number of criminals according to a Cobb-Douglas function as it is the simplest specification that satisfies assumptions for $\alpha\left(N_{B}\right)$ outlined in the previous subsection. I set elasticity parameter $\mu$ of crime to the number of criminals in $\alpha\left(N_{B}\right)=N_{B}^{\mu}$ to $1 / 2 .{ }^{19}$

Table 1 summarizes parameters of the model and their targets. Using these I calculate the implied steady state equilibrium.

\footnotetext{
${ }^{17}$ To estimate what percentage of homicides ends up in a jail sentence, El Faro (2016) assumes that every individual sentenced to jail in 2015 commited on average five homicides. To obtain the comparable rate for Guatemala, I assume that the number of homicides commited by the sentenced individuals is proportional to the overall homicide rate. Thus I multiply the ratio of commited individuals (available at the INE website) to the number of homicides by five and the ratio of the homicide rates in Guatemala to El Salvador respectively. I use the latest year for which the number of commited individuals is available -2012 , when the homicide rate was 33 .

${ }^{18}$ The penal codes are available at https://oig.cepal.org/sites/default/files/1999_hnd_d144-83.pdf for Honduras, https://www.oas.org/dil/esp/Codigo_Penal_El_Salvador.pdf for El Salvador, http://leydeguatemala. com/codigo-penal/homicidio/3029/ for Guatemala.

${ }^{19}$ Alternatively one can calibrate the scale parameter of the crime function $\alpha\left(N_{B}\right)$ to match existing direct crime cost estimates, size of the prison population, number of active criminals proxied by gang membership or any combination of these. As I show later in the section, the model implied moments are close to data, thus implicitly assuming a unity scale factor as I do here seems acceptable.
} 
What is the implied cost of crime in the model? Given that the output per capita is $y=$ $p(1-\alpha) N_{L}$, the cost of crime is: $:^{20}$

$$
-\frac{y^{\text {crime }}-y^{\text {nocrime }}}{y^{\text {nocrime }}}=-\frac{(1-\alpha) N_{L}-N_{L}^{\text {nocrime }}}{N_{L}^{\text {nocrime }}}=\underbrace{\alpha}_{\text {direct cost }}+\underbrace{(1-\alpha) \frac{N_{L}^{\text {nocrime }}-N_{L}}{N_{L}^{\text {nocrime }}}}_{\text {indirect cost }}
$$

The direct cost captures the decline in GDP due to crime given observed employment. It is 13.3 percent of GDP for Honduras, 19.5 percent of GDP in El Salvador and 6.4 percent in Guatemala, equivalent to $\alpha$, the share of observed output lost to criminals (see Table 2). These numbers are in line with existing estimates of the direct crime cost in the literature (see crosses in Figure 4).

Empirical components of violence costs vary widely depending on which costs are included. For example, my measure of the crime cost includes not only forgone labor income (the largest crime cost component in IDB (2017), for example) but also firms' profit. On the other hand, my measure does not include prison or private or public security costs explicitly, although it is possible to include these in the model as well. However this would require additional parameters and their calibration. Homicide costs reported in IDB (2017) are much lower than those depicted on Figure 4, because the value of stolen goods is not included in their estimation.

One of the advantages of using the model is the possibility of estimating the indirect effect of crime. It is impossible to calculate it directly from the data because doing this requires an estimate of the counterfactual level of employment in the absence of crime. However, it can be calculated using the model by setting $\alpha=0$.

\begin{tabular}{lccc}
\hline Crime cost & Honduras, 2016 & El Salvador, 2015 & Guatemala, 2015-17 \\
\hline Direct & 13.3 & 19.5 & 6.4 \\
Indirect & 3.0 & 6.7 & 0.9 \\
Total & 16.3 & 26.2 & 7.3 \\
\hline Memo: & & & \\
Homicide rate & 59.1 & 108.6 & 26.5 \\
\hline
\end{tabular}

Table 2. Implied crime cost as percent of GDP

The model implies that the indirect cost of crime is 3.0, 6.7 and 0.9 percent of GDP for Honduras, El Salvador and Guatemala cases respectively, which is in addition to the direct cost. This is because output and the employment rate are lower in the presence of crime. The labor demand is lower because firms post less vacancies expecting lower returns from production. The labor supply is lower because workers foresee lower returns from working and others are in prison or engage in criminal activities instead of working.

The only estimation that in the literature of indirect cost of crime that I am aware of is Penate and others (2016), which does it for El Salvador for 2014, when the homicide rate

\footnotetext{
${ }^{20}$ Note that in the presence of crime $N_{L}$ can be lower due to outward migration. This channel is absent from the current model.
} 


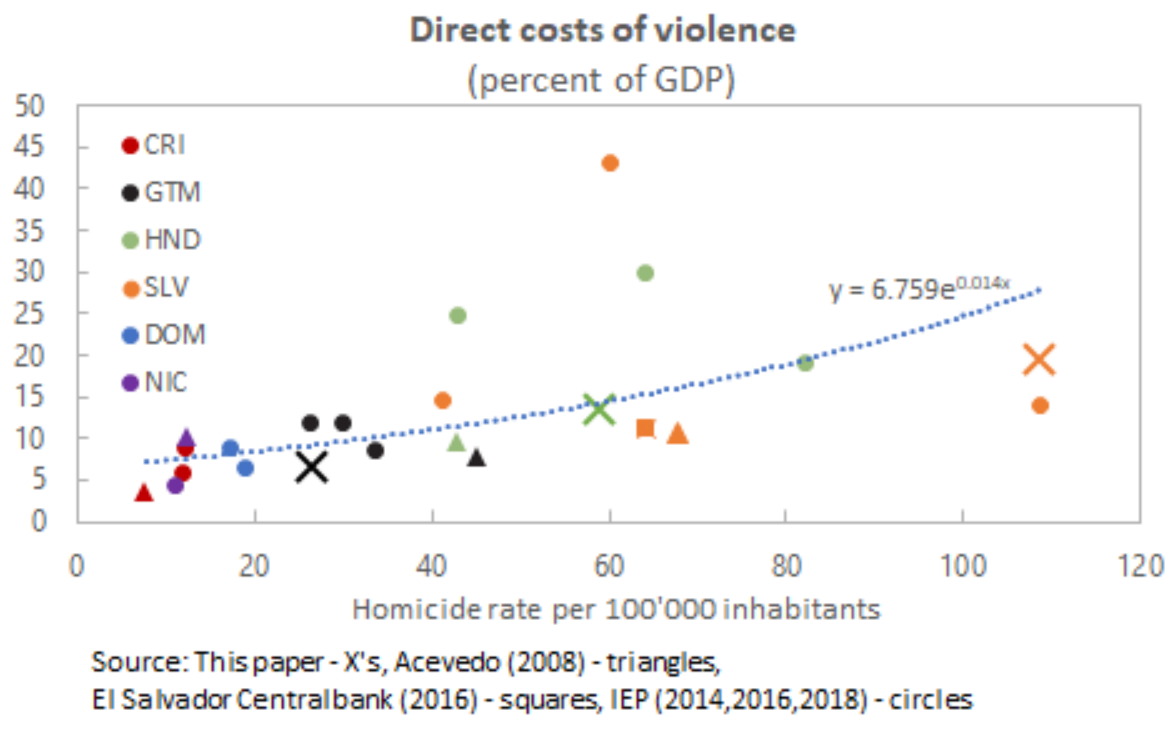

Figure 4. Model implied costs of crime in comparison with existing estimates. The fitted line is calculated excluding estimates of this paper.

was 64.2 making it comparable to Honduras 2016 when the rate was 59.1. Indeed, the model implied indirect cost ( 3 percent of GDP) is in line with lost production and investment due to crime, the measure of indirect cost of crime in Penate and others (2016), estimated at 4.8 percent of GDP.

Next, I verify that the model implies reasonable numbers for other variables not used in calibration: prison population and the number of criminals. For simplicity I do this only for the case of Honduras, the most relevant high-crime case. The calibrated parameters for the case of Honduras imply that about 1.1 percent of population are in prison in equilibrium. According to the World Prison Brief data - adjusting for the difference in population and economically active population - about $1 / 2$ percent of population was in Honduras prisons in $2016 .^{21}$ Where does the difference come from? One possibility is that convicted murderers are granted lighter sentences than prescribed by law perhaps for cooperation and testimony (UNODC (2012)). However, remember that the model assumes that after leaving prison ex-convicts are as likely to be employed as individuals that have never been to jail. To account for the latter the effective prison population in the model is larger.

The model implies that active criminals, $N_{B}$, constitute about $3 / 4$ percent of population, equivalent to about 67 thousand individuals in 2016. How reasonable is this number? Due to lack of data of active criminals, I compare the model's implication to estimated gang membership in Honduras. The estimates of UNODC, USAID, US State Department of the gang membership of the two largest gangs MS13 and Barrio 18 (InSight Crime (2015)) adjusted for population growth suggest between 13 and 45 thousand individuals in 2016 with some studies suggesting numbers up to 300 thousand members (World Bank (2011)). Since crime is not limited just to gang membership, I view the model implied number as reasonable.

\footnotetext{
${ }^{21}$ Using that the total population of Honduras in 2016 was $8.5 \mathrm{mln}$ and the economically active population was about $3.9 \mathrm{mln}$.
} 


\section{Policy Experiments}

Now I turn to the question that motivated the use of the model in the first place: interdependence of output and crime. Figure 5 shows two different cases of this relationship. Steady state values of both output and crime rate in the original state are normalized to 100.

The model implies that on average a one percent increase in output per capita implies about $1 / 2$ percent decline in crime, for the baseline high crime case - Honduras, 2016. To see this, Figure 5a shows how better economic situation, driven by labor productivity, affects crime. It plots crime rate $\alpha$ on the y-axis and observed GDP per capita $(1-\alpha) p N_{L}$ on the $\mathrm{x}$-axis. Labor productivity varies from 80 percent of its steady state value to 120 percent of its steady state value where the markers correspond to 5 percent increases. First, the model implies that as productivity improves, legal activity naturally becomes more attractive relative to criminal activity for individuals. Although existing criminals also receive higher income from higher output, the higher profitability of the legal employment outweighs this effect. Higher firm profits in turn encourage more firms to enter the market, thereby expanding employment. Second, the effect is non-linear: the positive effect on crime is decreasing as productivity grows. Third, presence of crime serves as a multiplier between productivity and observed output: if productivity increases (decreases) by 10 percent, output per capita increases (decreases) by about 11 percent, while if the increase (decrease) is twice as big, output increases (decreases) by 23 percent.

As expected, the positive effect of output growth is larger (smaller) for the case of El Salvador (Guatemala). This is represented by a steeper curve in the case of El Salvador and a flatter curve in the case of Guatemala, both relative to the Honduras case (see Figure 5a). In the case of El Salvador, a one percent increase in output decreases crime by $2 / 3$ percent, while in the case of Guatemala the effect is close to the baseline case: 0.50 percent ( 0.52 percent in the Honduras case). The latter suggests that the positive effects of better economic activity on crime are similar for a broad set of crime levels. The nonlinearity of negative crime response to worse economic conditions is especially precarious for the case of El Salvador (see Figure 5a) - the model predicts that one percent lower output would lead to $3 / 4$ percent higher crime on average if the decline is less than five percent and the average effect increases to 1 percent for the decline between five and ten percent.

The model suggests that on average a decrease of about $51 / 4$ percent in crime leads to about one percent increase in output per capita, again for the baseline case of Honduras 2016. Figure $5 \mathrm{~b}$ presents how changes in judicial system effectiveness, $\eta$, impact output and crime. The markers correspond to 5 percent increases in $\eta \cdot{ }^{22}$ In the case of Honduras the 20 percent increase in police effectiveness - so that the prosecution rate increases from 4 percent to 4.8 percent, still a very low number in world standards - decreases crime significantly - by about 7 percent. At the same time output per capita level increases by 11/4 percent. Moreover, the positive effect on output decreases as the security situation improves. The effect is likely to be even smaller after costs of higher police expenditures to improve effectiveness are considered. These numbers are consistent with the new reducedform evidence (IMF (2019)) of a much lower effect of crime on growth than previously

\footnotetext{
${ }^{22}$ Clearly, the effect is again non-linear as indicated by unequal spacing between the markers.
} 


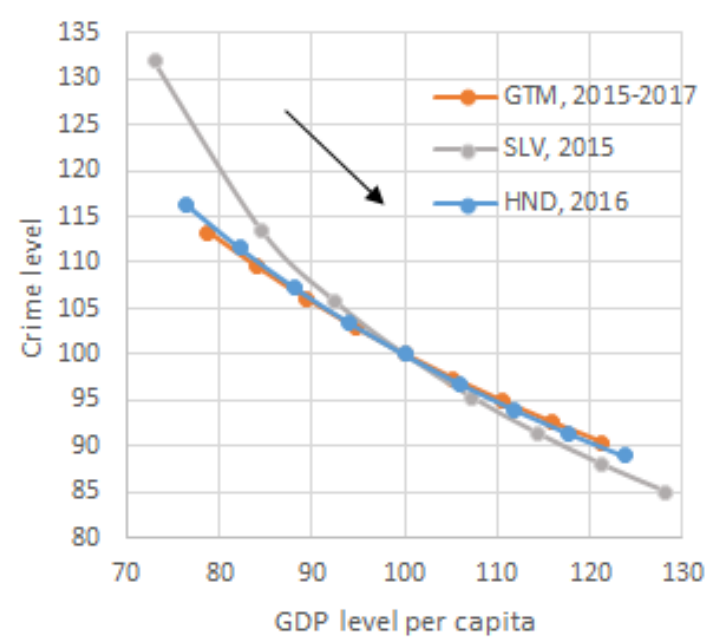

(a) Driven by labor productivity, $p$

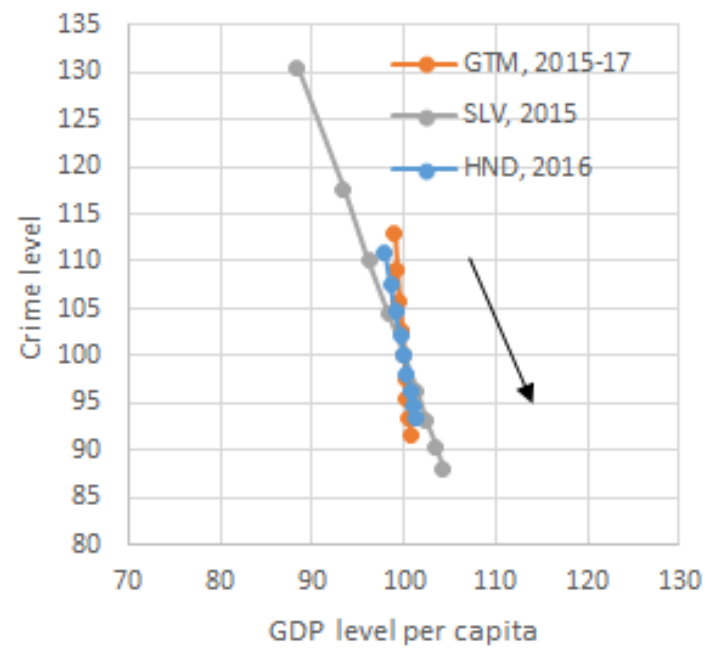

(b) Driven by judicial system effectiveness, $\eta$

Figure 5. Crime and output locus. The arrows show the direction in which the parameters increase

expected (World Bank (2011)). The model is also consistent with a so far low acceleration in Honduras growth given the significant 30 percent reduction in homicides since $2011 .^{23}$

Relative to the Honduras case, the positive effect of lower crime due to a more effective judicial system on output is larger (lower) for El Salvador (Guatemala) (see Figure 5b). To reach the same one percent increase in output per capita, crime in El Salvador and Guatemala needs to come down by $23 / 4$ and $123 / 4$ percent respectively. This is also expected given the difference in crime levels among the three countries. Clearly, the observed (negative) equilibrium relationship between output and crime depends on the underlying driver as Figure 5 shows. For example, the slope of the curve is much steeper in Figure $5 \mathrm{~b}$ than in Figure 5a.

Next, I briefly show effects of the four policy parameters on crime and economic activity: leisure value of being unemployed, barriers to entry for firms, attitudes toward unionization and exogenous criminals inflow. The results of these experiments are summarized in Figure 6.

As Figure 6a shows, increasing the value of being unemployed, $z$, reduces crime and improves output. In the model the effects are small because the calibrated value is very small - 3.2, 2.0 and 0.2 percent of GDP for Honduras, El Salvador and Guatemala cases respectively. Increasing $z$ makes crime less attractive by reducing the gap between the payoff of being a criminal and looking for a job. Thus, less people become criminals which in turn improves attractiveness of legal activities, posting of jobs by firms and, in the end, output. However, the effect is small and is not welfare-improving as, for example, the cost of a 20 percent increase in leisure value - equivalent to 0.6 percent of GDP in the case of

\footnotetext{
${ }^{23}$ For example, World Bank (2011) predicted 0.7 percentage point increase in the annual growth rate if the homicide rate were to go down by 10 percent.
} 


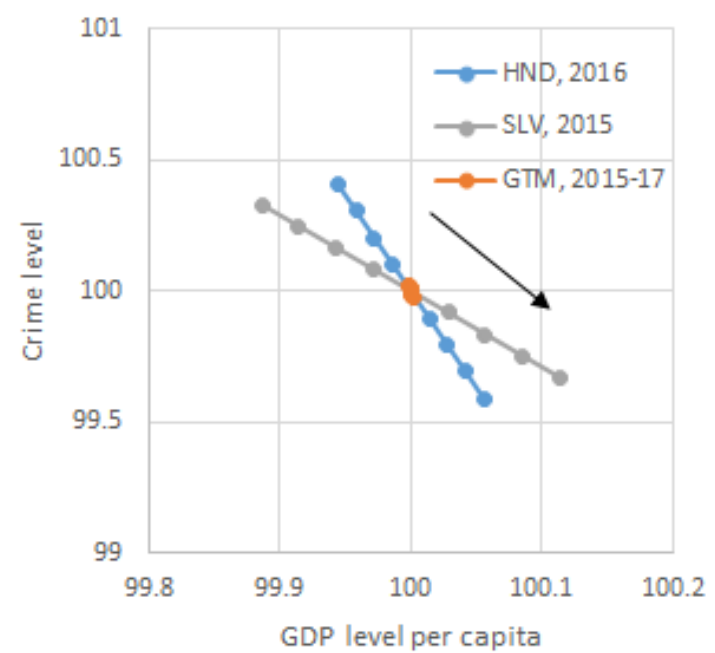

(a) Driven by leisure value/outside activities, $z$

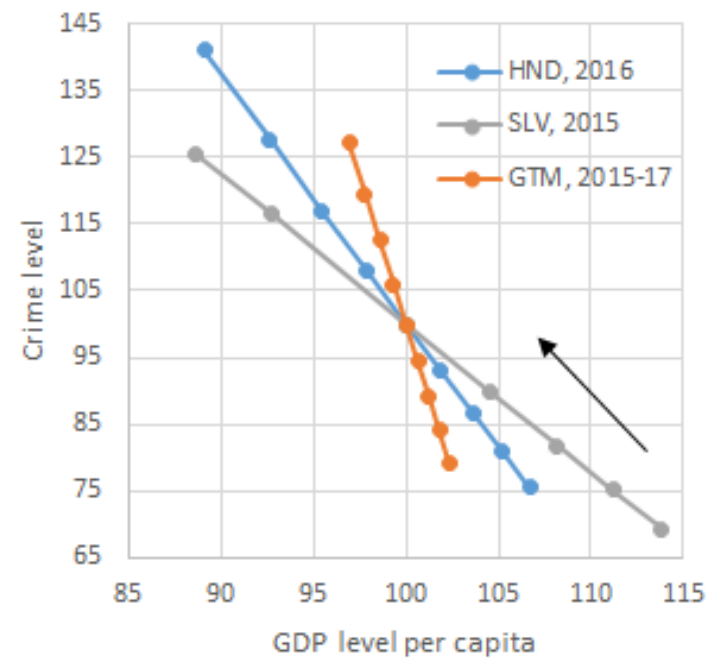

(c) Driven by worker's bargaining weight/unionization, $\beta$

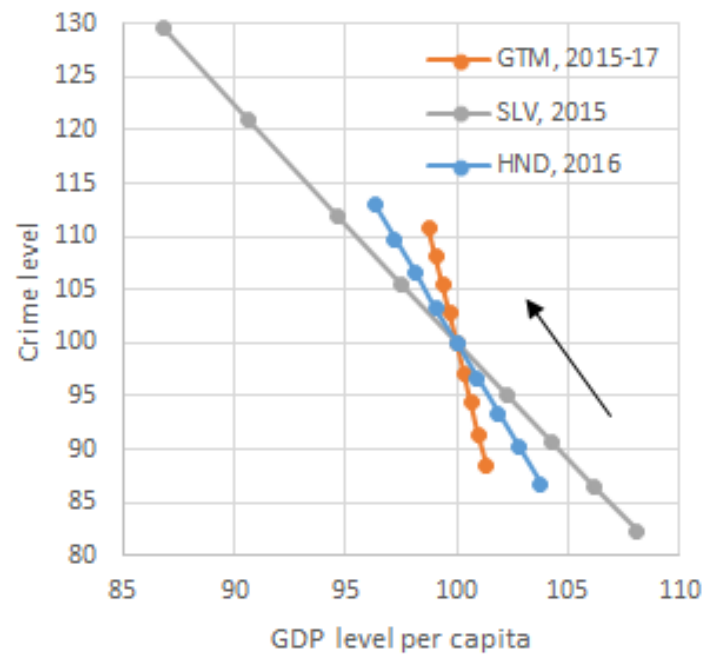

(b) Driven by vacancy cost/barriers of entry, $c$

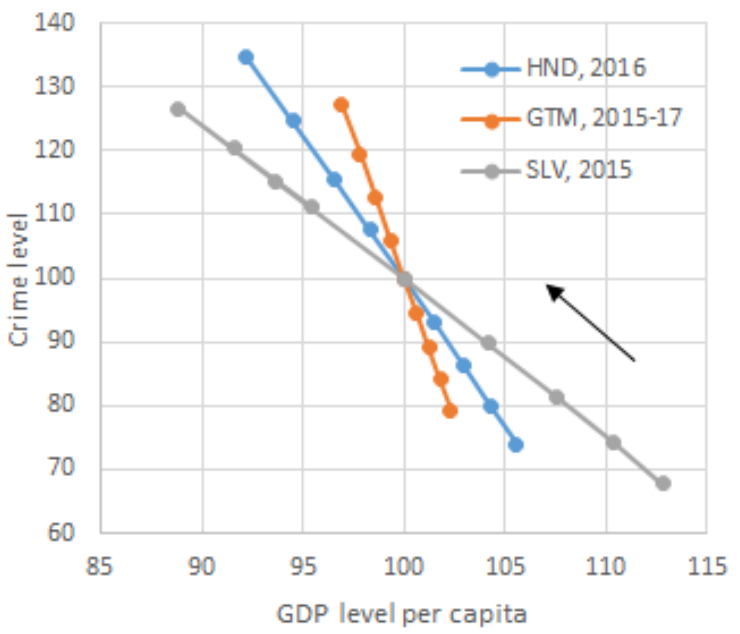

(d) Driven by exogeneous increase in criminal supply, $b_{s}$

Figure 6. Results of the policy experiments. The arrows point at the direction in which the corresponding parameter increases

Honduras - improves GDP only by 0.1 percent (see Table 1). Why? Because by discouraging criminal activities, $z$ also discourages job seeking and in the medium-term does not improve job prospects.

In reality, what constitutes $z$ matters. For example, providing recreational activities to atrisk youth or organizing police fairs as is currently done in Honduras can increase trust in policing and, as a result, indirectly boost police effectiveness, $\eta$.

Reducing vacancy cost is beneficial for both output and security (see Figure 6b), especially for high crime levels. Vacancy cost can be interpreted as hiring expenses, on-the-job training and, most importantly, a one-time barrier to entry transformed into an annuity. 
Decreasing vacancy costs boosts vacancies, the job finding rate and the value of legal activities and employment. As relative attractiveness of criminal activities falls, the numbers of criminals decreases reducing the crime rate. The model implies that 10 percent reduction in the vacancy cost per period reduces crime by 5.7, 6.6, 9.4 percent and improves output by 0.6, 1.9, 4.3 percent for Guatemala, Honduras and El Salvador cases respectively. Reducing barriers to entry and improving human capital are ways of archiving this. Reduction of barriers may have an even more positive effect if firms and workers are heterogeneous in productivity. Indeed, since a fixed entry cost prevents low productivity firms from entering the market altogether, reducing it will not only increase vacancies, but will also employ low productivity individuals that would not have found a job in higher productivity firms otherwise.

Figure $6 \mathrm{c}$ shows that in the presence of crime, boosting attractiveness of legal activities by increasing wages through higher unionization among workers would backfire. The reason for this is twofold. First, such a policy does not increase the total gains from a match between a worker and a firm. Second, in the presence of crime the incentives for firms to enter the labor market are already weak. Increasing the bargaining weight of workers reduces it further, resulting in even fewer vacancies. This in turn leads to a lower job finding rate and lower employment, encouraging criminal activity as an alternative. In reality the negative effect on the economy is likely to be significantly lower, as higher unionization is likely to push the economy towards informality rather than criminal activity, the only alternative to legal activity in the model.

Finally, Figure 6d shows effects of exogenous increase in criminals. I formalize it by introducing a scale factor for the equilibrium transition rate, $b$. In other words, the equilibrium rate $b$ is augmented in equation 12 by a factor that varies from 0.8 to 1.2 in 5 percent increments ${ }^{24}$ This means that more unemployment individuals are are converted into criminals. This captures the idea that the crime in the region is subject to exogenous causes such as amount of drug trafficking. The results of this simulation are straightforward: higher transition rate to criminal activity is detrimental for all calibration cases and the higher the initial crime level, the worse the effects of such shock are.

\section{Policy Recommendations}

The overarching policy recommendation of the model is the observation articulated in Becker (1968) that criminals are rational individuals who compare the expected cost and benefit of committing crimes with those of legal activities. In other words, reducing the profit of crime relative to the legal activity should be a key policy goal. As the model demonstrates, a combination of higher returns to legal activities (productivity), lower barriers to entry and increased police effectiveness should generate lower crime rates.

Out of these three objectives and since resources are often limited, policy recommendations ideally should be assessed per currency unit spent. In other words, one should be able to estimate how much one currency unit spent on a specific policy affect each of the model parameters. This is easier to do for some parameters than for others. For example,

${ }^{24}$ That is in all previous simulations and calibrations this factor is equal to one. 
increasing unemployment insurance or conditional cash transfer for likely unemployed should only affect the unemployment flow value, $z$ (minus a transaction cost). However, it is more complicated for infrastructure investment since in this case one needs to estimate effect of an additional currency unit spent on labor productivity, $p$. It is even more complicated in the case of judicial system reform or police spending as it will affect parameter $\eta$ in the model, which corresponds to the judicial system effectiveness. The latter would require data not currently available publicly (to my knowledge). Having said that and given lack of data to cost specific parameters, I make model recommendations based on the broad patterns of policy experiments in the previous section.

The model suggests that for very high crime levels (such as the 2015 El Salvador case), improving policing and strengthening the criminal justice system is the most effective in bringing crime down. This should allow for swift convictions and punishments. In this context regional cooperation is crucial, given positive externalities of better judicial systems for other countries in the region and external drivers of crime. Still, measures aimed at this goal are not likely improve output significantly apart from reducing direct crime costs especially if economic opportunities were lacking in the first place.

As the level of crime declines, the policy should start focusing on improving return from legal activities. This is also true if improving effectiveness of the judicial system further is costlier than boosting labor productivity by the amount that has a similar predicted effect on crime. Thus, policies that reduce barriers to entry for new firms and overall business climate via friendlier regulations, more efficient tax system, better infrastructure will be key to promote employment and increase the profit of legal activities fostering legal job creation. The policies should also aim at improving quality and universality of basic education - the backbone of labor productivity.

The policymakers should ensure frictionless reintegration of ex-convicts in the productive sector. This channel assumed to work perfectly in the model and is critical in reality. For example, the government can provide basic skills required to work in or after prison to bolster re-integration of ex-convicts in the productive sector. In this sense the El Salvador's program "Yo Cambio" that shared this objective was likely helpful in reducing the homicide rate post-2016 (IMF (2019)). Quality of prisons facilities and personnel should also improve to ensure adequate policing and prevent crime and gang formation within prisons, which would hamper the re-integration process.

\section{Conclusion}

While crime remains a headline issue for the Northern Triangle, not enough work has been directed towards quantifying the effects of crime in the region, examining its drivers, and formulating solutions. The reasons are many, including data limitations, capacity and resource constraints, a bias towards punitive rather than analytical or preventive measures in public policy, and sensitivities around the topic. In addition, despite substantial research done in economics on the area of crime, the quantitative effects of crime on economic growth are still not fully understood.

The model presented in this paper is an initial step towards a framework for joint evaluation of the interplay between labor market and crime policies. Even given its simplicity it 
captures available crime and economic data reasonably well and can help structure policy discussion. Its main advantage, however, is that it can analyze the relationship between output and crime without running into the issue of reverse causality. Using the model I can also study mechanisms driving the relationship.

Specifically, tackling crime will require a combination of (i) prevention interventions that increase expected benefits from legal and non-violent activities, (ii) improving policing and other deterrence activities, and (iii) strengthening the criminal justice system to speedup processes, thus increasing the cost of committing crimes while at the same time promoting the reintegration of ex-convicts in the productive economy.

Given limited resources available, it is critical to invest in data collection and monitoring, and adjust strategies in real time. Ideally, interventions should be targeted to the most needed areas and adjusted based on evidence. For example, it is important to target at-risk population and youth in particular for vocational programs and social programs. While providing recreational activities can help reduce crime in the short-run and obtain trust, in the medium run these programs should also invest in job training and education. There is a significant role for the private sector, especially in specific skill formation and family support programs.

Even with all of the policy recommendations are implemented, importance of stable and inclusive economic growth cannot be overstated. As, the model demonstrates, it is one of the most consistent drivers of crime reduction as it tilts incentives of unemployed individuals toward productive activity. 


\section{REFERENCES}

Acevedo, C., 2008, “The economic costs of violence in Central America," San Salvador: National Security Consul (in Spanish).

Becker, G., 1968, “Crime and Punishment: An Economic Approach,” Journal of Political Economy 76, no. 2 (Mar. - Apr., 1968): 169-217.

El Faro, 2016, "La Fiscalia solo ha podido llevar a tribunales uno de cada 10 homicidios cometidos en 2015," El Faro.

Engelhardt, B., G. Rocheteau, and P. Rupert, 2008, "Crime and the Labor Market: A Search Model with Optimal Contracts," Journal of Public Economics.

Hosios, A., 1990, "On the Efficiency of Matching and Related Models of Search and Unemployment," The Review of Economic Studies Vol. 57, No. 2 (Apr., 1990), pp. 279298.

Huang, C., D. Laing, and P. Wang, 2004, "Crime and Poverty: A Search-Theoretic Approach," International Economic Review.

IDB, 2017, "The Cost of Crime and Violence: New Evidence and Insights in Latin America and the Caribbean," Inter-American Development Bank, Washington, DC.

IEP, 2014, “The Economic Cost of Violence Containment,” Techn. rep., Institute for Economics and Peace.

—_, 2016, “Economic Value of Peace,” Techn. rep., Institute for Economics and Peace.

—_, 2018, “Economic Value of Peace," Techn. rep., Institute for Economics and Peace.

IMF, 2016, “El Salvador 2016 Article IV Consultation Staff Report,” Techn. rep., IMF.

—_, 2018, "Honduras 2018 Article IV Consultation Staff Report,” Techn. rep., IMF.

_- 2019, Paving the Way to Sustained Growth and Prosperity in Central America, Dominican Republic and Panama (International Monetary Fund).

InSight Crime, 2015, “Gangs in Honduras,” https://www.insightcrime.org.

_ 2017, "Homicides in Guatemala: Analyzying the data," https://www.insightcrime.org.

Lagarde, C., 2015, “Addressing Corruption - Openly,” Washington D.C.

Nazario, S., 2016, “How the Most Dangerous Place on Earth Got Safer," New York Times.

Penate, M., K. Mendoza, J. Quintanilla, and C. Alvarado, 2016, "Estimation of the Economic Cost of Violence in El Salvador in 2014," Occasional Documents of the Central Reserve Bank of El Salvador.

Pissarides, C., 2000, Equilibrium Unemployment Theory (The MIT Press).

Shimer, R., 2005, “The Cyclical Behavior of Equilibrium Unemployment and Vacancies," American Economic Review. 
UNODC, 2012, "Transnational Organized Crime in Central America and the Caribbean: A Threat Assessment," United Nations Office on Drugs and Crime, Vienna, Austria.

World Bank, 2011, "Crime and Violence in Central America: Developmental Challenge," World Bank, Washington D.C. 